\title{
Galls on smaller leaves do not refute the Plant Vigour Hypothesis
}

\author{
White, TCR.* \\ School of Agriculture Food and Wine, Waite Agricultural Research Institute, \\ The University of Adelaide, Glen Osmond, South Australia 5064, Australia \\ *e-mail: tcrwhite@optusnet.com.au
}

Santos et al. (2011) report that they have refuted Price (1991) Plant Vigour Hypothesis. They have found that a curculionid beetle, Prospoliatabicolorata, that galls the petioles of the leaves of a pioneering shrub, Miconiaprasina, is more abundant and survives better on leaves that are shorter, lighter and smaller in area, and then argue that “... smaller leaves should possess higher rates of resource quality essential for larval development ...".

However, they have not refuted this hypothesis, nor do they provide evidence that smaller leaves are more nutritious. The majority of herbivores feed preferentially upon the new growth of plants. They are flush-feeders (White, 2009). Therefore, the more vigorous this growth, and thus the greater the inflow of high quality sap into that growth, the greater chance such herbivoreswillhave of surviving and growing to maturity. And insects that form galls are quintessential flush-feeders. Whether they are chewers or sap-suckers, they must, unlike their freeliving counterparts, induce the plant to divert resources destined for its own growth, first to the formation of a gall, and then to the continued importation of nutrients into that gall to feed the growing larva within. To do this they must attack tissues that are still actively growing. The galls of $P$. bicolorata are situated on the petiole of the leaves of its host, an ideal place to intercept nutrients otherwise destined for the growing blade of the leaf. But Santos et al. (2011) did not measure growing leaves. They based their conclusions on old mature leaves collected in September at the beginning of the dry season.

Therefore, an alternative and more plausible hypothesis to explain Santos et al.'s (2011) findings, is that the small size of the mature leaves is a consequence not a cause. Successful galls would result in smaller leaves, rather than smaller leaves producing successful galls. Female weevilswould lay their eggs in the soft petioles of stillexpanding leaves. Their larvae, like those of all other gallers, would establish and grow more successfully on the most vigorous young leaveswhile they are still actively growing. However, those leaves are unlikely to grow as big as leaves that are not attacked by a galler. This is because the galls and their contained larvae act as "nutrient sinks", diverting the flow of high-quality sap from the growing leaves to their own continued growth. Leaves that are thus deprived of much of these nutrients are likely to grow less and be smaller at maturity than those leaves that were not attacked by gallers.

Curiously, the study Santos et al. (2011) cite as the reason for selecting the size of leaves as a measure of vigour, and thus of the preferred site for oviposition by gall-formers (Clancy et al., 1993), states quite unequivocally that "... the size of a mature leaf did not appear to be an important factor determining which leaves were selected for oviposition among the leaves available." Additionally they found that "... survival was weakly biased towards smaller leaves".

Santos et al. (2011) finally say that while their results also do not support White (1969) Plant Stress Hypothesis, they intend to test this in the future. However, unless $P$. bicolorata larvae "double-dip" by subsequently feeding on an outflowing of nutrients from senescing leaves and/or galls (White, 2010) this species is unlikely to be a suitable animal with which to test the stress hypothesis.

\section{References}

CLANCY, KM., PRICE, PW. and SACCHI, CF., 1993. Is leaf size important for a leaf-galling sawfly (Hymenoptera: Tenthredinidae)? Environmental Entomology, vol. 22, p. 116-128.

PRICE, PW., 1991. The plant vigor hypothesis and herbivore attack. Oikos, vol. 62, p. 244-251.

SANTOS, JC., TAVARES, CB. and ALMEIDA-CORTEZ, JS., 2011. Plant Vigor Hypothesis refuted: preference-performance linkage of a gall-inducing weevil on small-sized host plant resources. Brazilian Journal of Biology, vol. 71, p. 65-69. http:// dx.doi.org/10.1590/S1519-69842011000100010

WHITE, TCR., 1969. An index to measure weather-induced stress of trees associated with outbreaks of psyllids in Australia. Ecology, vol. 50, p. 905-909. http://dx.doi.org/10.2307/1933707

-, 2009. Plant vigour versus plant stress: a false dichotomy. Oikos, vol. 118, p. 807-808. http://dx.doi.org/10.1111/j.16000706.2009.17495.x

-, 2010. Why do many galls have conspicuous colours? An alternative hypothesis revisited. Arthropod-Plant Interactions, vol. 4, p. 149-150. http://dx.doi.org/10.1007/s11829-010-9096-1 